\title{
Experimental and CFD analysis of rotary multi vane expander for small capacity generation
}

\author{
Mohammad Mahardika ${ }^{1, *}$ \\ ${ }^{1}$ Mechanical Engineering Department, Institut Teknologi Nasional Bandung, 40124 Bandung, \\ Indonesia
}

\begin{abstract}
Every year, Indonesia's population increase so as energy demand. To fulfill Indonesia's energy needs, the capacity of energy production should be increased. Indonesia government has made a solution by propose $35.000 \mathrm{MW}$ program to increase energy production and electrification ratio in Indonesia. An insulated area where electricity did not reach, has many problem to get electricity such as limited infrastructure, low fuel energy content, and expensive turbine. To solve these problem, multi-vane expander (MVE) can be used to extract the low energy and is cheap. MVE have many advantages such as cheap, easy to manufacture, able to operate with 2 phase, and able to low speed operation. But, the disadvantage of this type of expander is leakage. In this paper, experimental and CFD analysis of MVE are conducted. The experiment generated power of 25.7 watt with isentropic and volumetric efficiency of $11.6 \%$ and $11.7 \%$ by using operating condition of 1.5 bar, $115.6{ }^{\circ} \mathrm{C}, 626$ $\mathrm{rpm}$, and mass flow rate of $80 \mathrm{~kg} / \mathrm{h}$. The CFD model of the expander is created with the same dimension and operating conditions as experimental. The result for isentropic efficiency is inversely proportional with mass flow rate and for volumetric efficiency, power, and expander rotation are directly proportional with mass flow rate.
\end{abstract}

\section{Introduction}

Every year, Indonesia's population increase so as energy demand. To fulfill Indonesia's energy needs, the capacity of energy production should be increased. Indonesia government has made a solution by propose $35.000 \mathrm{MW}$ program to increase energy production and electrification ratio in Indonesia. Indonesia electrification ratio in 2016 is $90 \%$, which means $10 \%$ of Indonesian people did not get electricity, generally in an insulated area [1]. An insulated area where electricity did not reach, has many problems to get electricity such as limited infrastructure, low fuel energy source, and expensive turbine to extract power. To solve these problem, small capacity $(1-100 \mathrm{~kW})$ power plant with Rankine cycle is chosen. This power plant can use fuel with low energy content such as biomass (wood, pellet, etc) which is the most available fuel in an insulated area. Rankine cycle which used low energy content such as solar, waste heat, and biomass are not efficient because the turbine works at off-design condition [2]. Expander that suitable for small capacity power plant is multi-

\footnotetext{
${ }^{*}$ Corresponding author: m.aziz.mahardika@itenas.ac.id
} 
vane expander (MVE). MVE is cheaper than other type expander such as screw [3] and can be used to extract the low energy [4]. Mahmoud used MVE to extract low energy content from vapor compression refrigeration system [5]. MVE have many advantages such as cheap, easy to manufacture, able to operate with 2 phase, and low-speed operation [6]. But, the disadvantage of this type of expander is leakage [7] and friction [8]. This paper explain the performance of MVE by using experimental and CFD method.

\section{Methodology}

The design process of MVE follows the guide from Badr [9]. The geometry of MVE is showed by Figure 1.

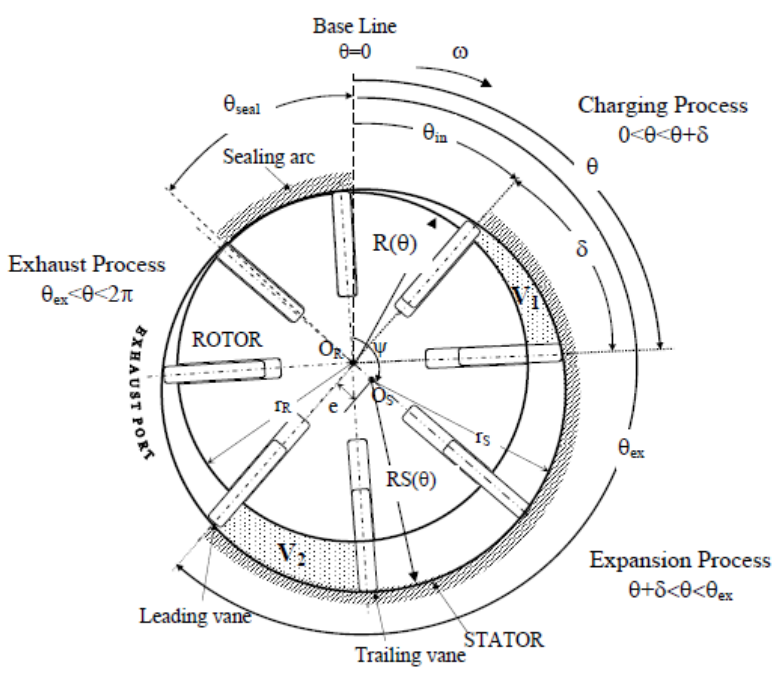

Fig. 1. Geometry of MVE with 8 vane [9].

The dimension and operating conditions of the MVE are stated on Table 1 and Table 2.

Table 1. Dimension Of MVE

\begin{tabular}{|ll|ll|}
\hline \multicolumn{2}{|c|}{ Dimension } & \multicolumn{2}{c|}{ Value } \\
\hline Rotor radius & $\mathrm{Rr}$ & 100 & $\mathrm{~mm}$ \\
\hline Eccentricity & $\mathrm{E}$ & 12.5 & $\mathrm{~mm}$ \\
\hline Angle between rotor and stator & $\Psi$ & $175^{\circ}$ & \\
\hline Stator radius & $\mathrm{Rs}$ & 112 & $\mathrm{~mm}$ \\
\hline Length & $\mathrm{L}$ & 55 & $\mathrm{~mm}$ \\
\hline Number of Vane & $\mathrm{N}$ & 4 & \\
\hline Inlet arc & $\Theta \mathrm{in}$ & $42.5^{\circ}$ & \\
\hline Outlet arc & $\Theta \mathrm{ex}$ & $135^{\circ}$ & \\
\hline Sealing arc & Oseal & $10^{\circ}$ & \\
\hline
\end{tabular}

Table 2. Operating Condition for Experimental

\begin{tabular}{|l|ll|}
\hline \multicolumn{1}{|c|}{ Operating Condition } & \multicolumn{2}{c|}{ Value } \\
\hline Inlet pressure & 1.5 & $\mathrm{bar}$ \\
\hline Mass flow rate & 80 & $\mathrm{~kg} / \mathrm{h}$ \\
\hline Rotation speed $(\mathrm{n})$ & 1500 & $\mathrm{rpm}$ \\
\hline
\end{tabular}


The performance of MVE was analyzed by using experimental and CFD method. By combining experimental and CFD method hopefully the MVE performance can be analyzed and improved.

\subsection{Experimental Setup}

Experimental scheme is showed on Figure 2. Water supplied flowed to the water tank. Water tank was used as reserve, before water went to the pump. Pump rose the pressure of water to 1.5 bar and then boiler changed the water into steam. Before steam reached expander (MVE) there were steam trap to make sure that fluid coming to the expander is fully steam, because the liquid phase will be extracted by steam trap. Flow meter was used to measure mass flow rate. Pressure and temperature were measured before enter expander using pressure gauge and thermocouple. Steam will rotate expander and generator. Generator and expander were connected by chain. The rotation of expander was measured by tachometer. Load resistance such as lamp is used to test the power generated by the expander. After leaving expander pressure and temperature were measured and steam went to the condenser.

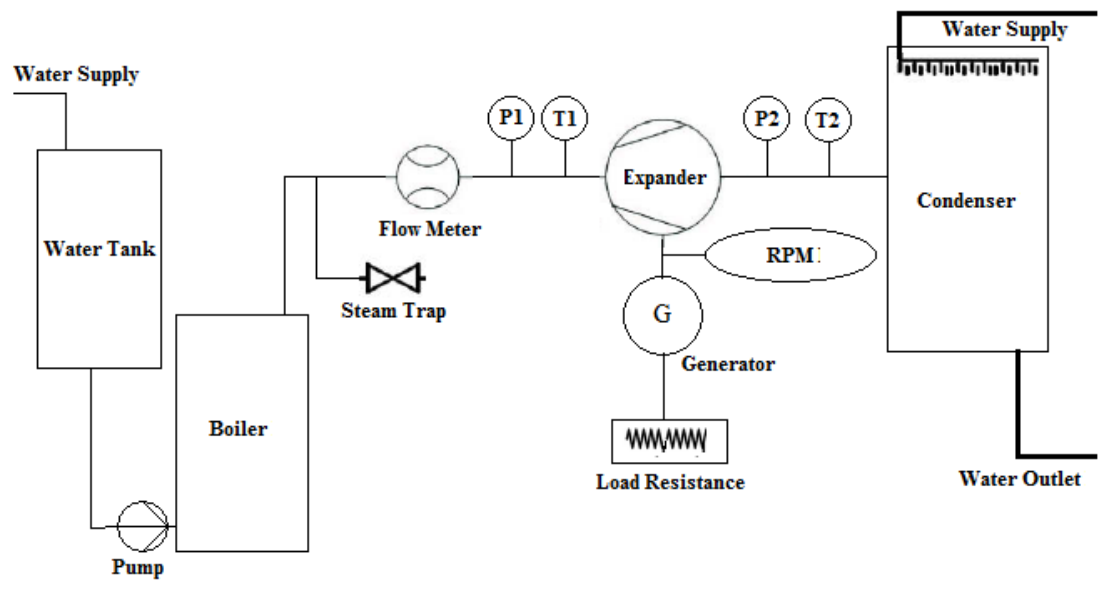

Fig. 2. Experimental scheme.

\subsection{CFD Setup}

CFD was used to analyze the process inside the expander. Model used to simulate the MVE were compressible, Navier-Stokes equations, turbulent, and condensing flow, additionally wet steam multiphase model was combined. The governing equations (mass conservation, momentum and energy) are stated as [10]:

Mass continuity equation :

Momentum equation :

$$
\partial \rho / \partial \mathrm{t}+\nabla \cdot(\rho \mathbf{v})=\mathrm{S}_{\mathrm{m}}
$$

$$
\partial / \partial \mathrm{t}(\rho \mathbf{v})+\nabla \cdot(\rho \mathbf{v} \mathbf{v})=-\nabla \mathrm{p}+\nabla \cdot\left[\mu\left(\nabla \mathbf{v}+\nabla \mathbf{v}^{\mathrm{T}}\right)\right]+\rho \mathbf{g}+\mathbf{F}
$$

Energy Equation :

$$
\partial / \partial \mathrm{t}(\rho \mathrm{H})+\nabla \cdot(\rho \mathbf{v H})=\nabla \cdot(\mathrm{k} \nabla \mathrm{T})+\mathrm{S}
$$

On the other hand, transient was used to simulate the expander with moving mesh method, because simulation of expander needed the mesh to be deformed at each time step. Figure 3 shows the mesh of the expander. Mesh must have same layer in small and large cavity area. 
Four layers had been chosen because it resulted in good mesh quality. The orthogonal quality and skewness parameter value are good enough.

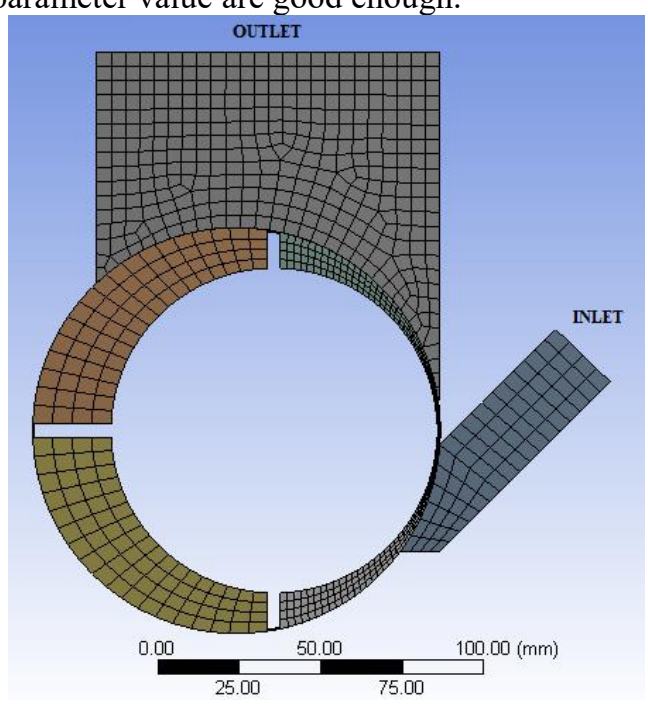

Fig. 3. Mesh of MVE model.

Simulation based on wet-steam model was used for turbulence model. Simulation was conducted for 5 different rotations, which are 600, 800, 1000,1200, and 1500. Each time steps the mesh are moved by 0.1 degree and expander are simulated for 5 revolution to make sure the solution are stable for each revolution. Operating conditions for simulation were different in inlet pressure. Inlet pressure for simulation was 6 bar. The other parameter was the same with experimental.

\section{Experimental and CFD Result}

\subsection{Experimental Result}

The steam from the boiler sucessfully rotated the expander and generated electricity, but, the performance was not to be expected. Expander can only generated electricity of 25.7 Watt with 1.5 bar of pressure and $80 \mathrm{~kg} / \mathrm{h}$ of mass flow rate. This low performance was caused by leaking of steam from the clearance of the vane and from the closing plate. As shown in Figure 4, not only from the clearance of the shaft and the plate cover but also inside the MVE, the steam can come across the other room by passing trough the vane clearance. The other losses is the friction of the vane with the wall. Leaking problem can be solved by using sealer in the clearance between the shaft and plate cover, but leaking from clearance of the vane is the main problem of this type of expander.
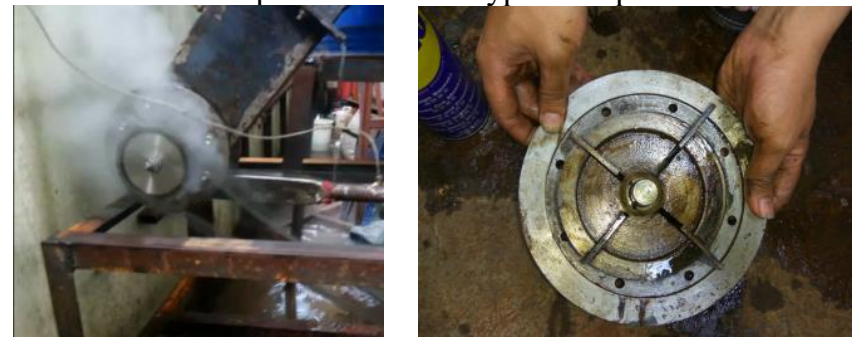

Fig. 4. Experimental process and inside of MVE 


\subsection{CFD Result}

Simulated CFD model was used to know the performance of expander. Figure 5 shows the relationship between rotation speed of expander and mass flow rate. The blue dotted line is the ideal line and the red dotted line is the simulated value. Ideal means that there are no leaks inside the expander while simulated value includes the leak. The result indicates that the mass flow rate from simulation is higher than the ideal. In $600 \mathrm{rpm}$ operation, the ideal mass flow rate is $14 \%$ from the simulation value, and in $2000 \mathrm{rpm}$ operation, the ideal mass flow rate is $30 \%$ from the simulation value. Ratio of ideal and simulation value are increased with rotation speed. Higher rotation speed will reduce the leakage problem because the time for steam to passing through between vane clearance is lower.

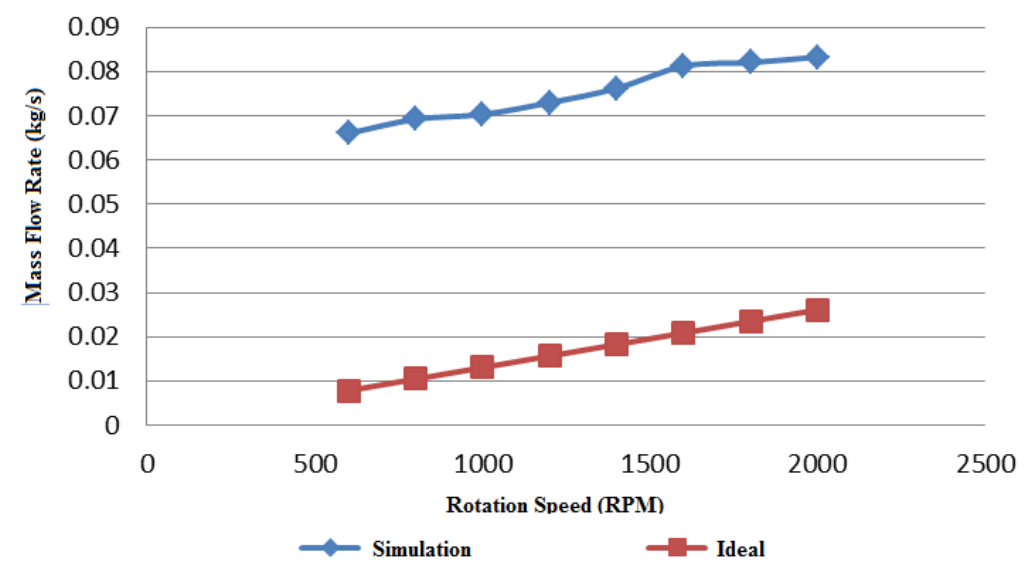

Fig. 5. Relationship rotation speed with mass flow rate.

Figure 6 explains the relationship between rotation speed and power. Ideal process has higher power than simulation because the leakage will decrease the power generated. Leakage problem reduces the power generated up to $60 \%$ from the ideal process. The higher the rotation speed will increase the power generated.

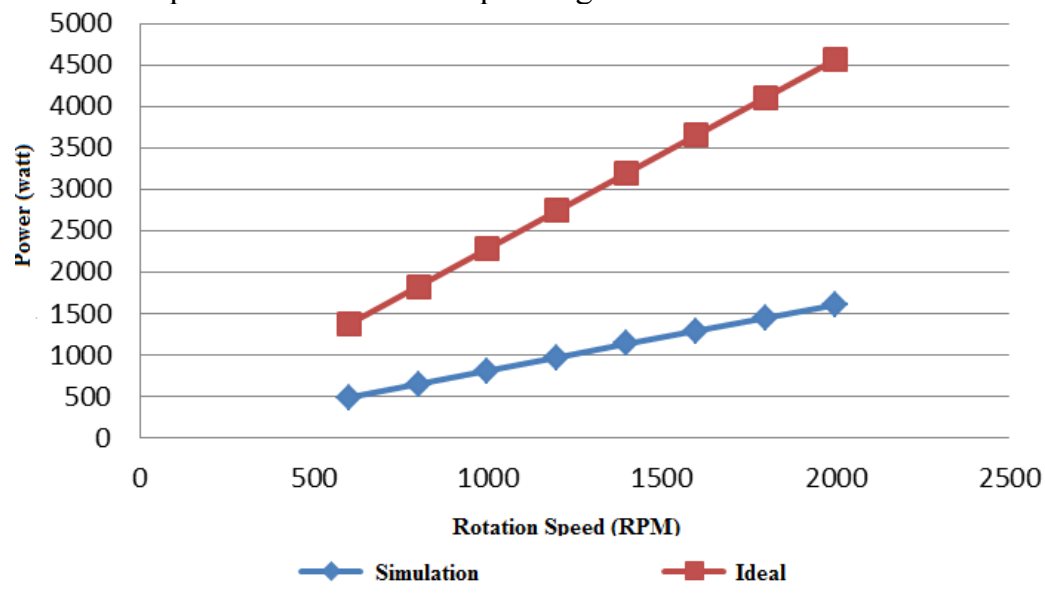

Fig. 6. Relationship rotation speed with power.

Figure 7 shows the relationship between the rotation speed and isentropic efficiency of expander. Increasing rotation speed will make the efficiency decrease, because the losses 
due to the friction will become higher. The increase of power losses by friction was higher than increase of power generated. So, the efficiency became lower.

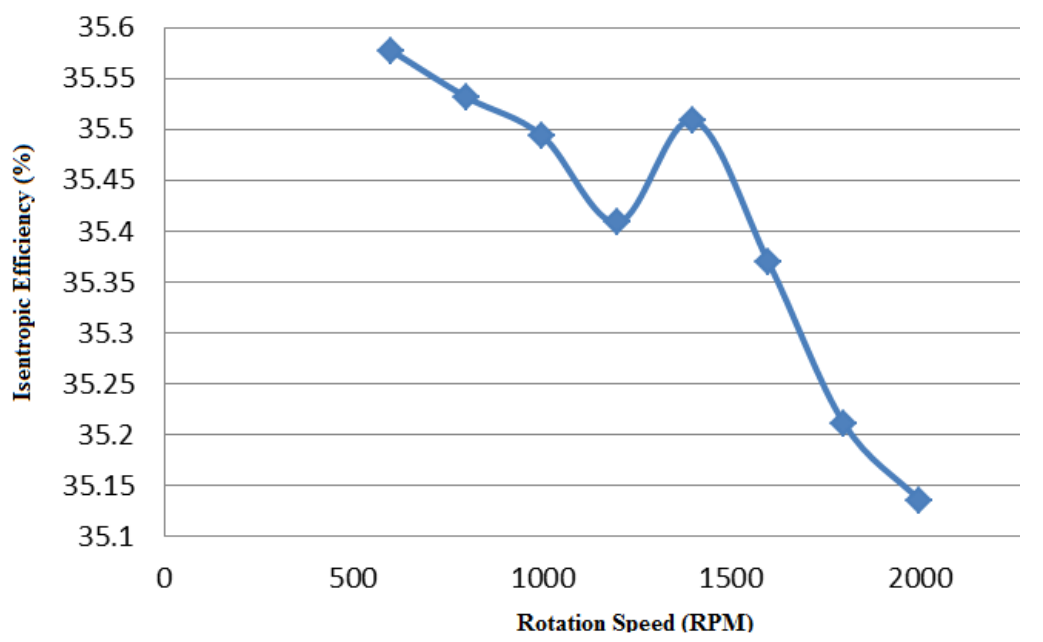

Fig. 7. Relationship rotation speed with isentropic efficiency.

\section{Conclusion}

Experimental and CFD had been conducted to know the performance of MVE. Experimental result shows that MVE can generate electricity of 25.7 watt from steam with pressure of 1.5 bar and mass flow rate of $80 \mathrm{~kg} / \mathrm{h}$. The experimental result shows that leakage is the main problem of this type of this expander. Thus, improvement must be made to increase the performance of MVE. CFD showed the relationship between rotation speed with mass flow rate, power, and efficiency. MVE has better performance in low speed operation, due to the lower friction losses, so the efficiency is higher.

\section{References}

1. DEN, Outlook Energi Indonesia 2015 (2014)

2. O. Badr, P.W. O’Callaghan, M. Hussein, S.D. Probert, J. Appl Energy. 16129 (1984)

3. O. Badr, S. Naik, P.W O’Callaghan, S.D. Probert, J. Appl Energy. 3994 (1991)

4. M. Imran, M. Usman, D.H. Lee, B.S. Park, Renew Sustain Energy Rev 571090 (2016)

5. A. Mahmoud, Analytical and Experimental Investigation of Rotary-vane Two-phase Expanders in Vapor Compression Refrigeration Systems. (2008)

6. O. Badr. S.D. Probert. P.W. O’Callaghan, J. Appl Energy 20207 (1985)

7. X. Jia, B. Zhang, L. Pu, B. Guo, X. Peng, Int J Refrig 34732 (2011)

8. O. Badr, S.D. Probert, P.W. O'Callaghan, J. Appl Energy 20253 (1985)

9. O. Badr, P.W. O’Callaghan, S.D. Probert, Appl Energy. 19, 159 (1985)

10. Ansys, ANSYS Fluent Theory Guide (2013) 